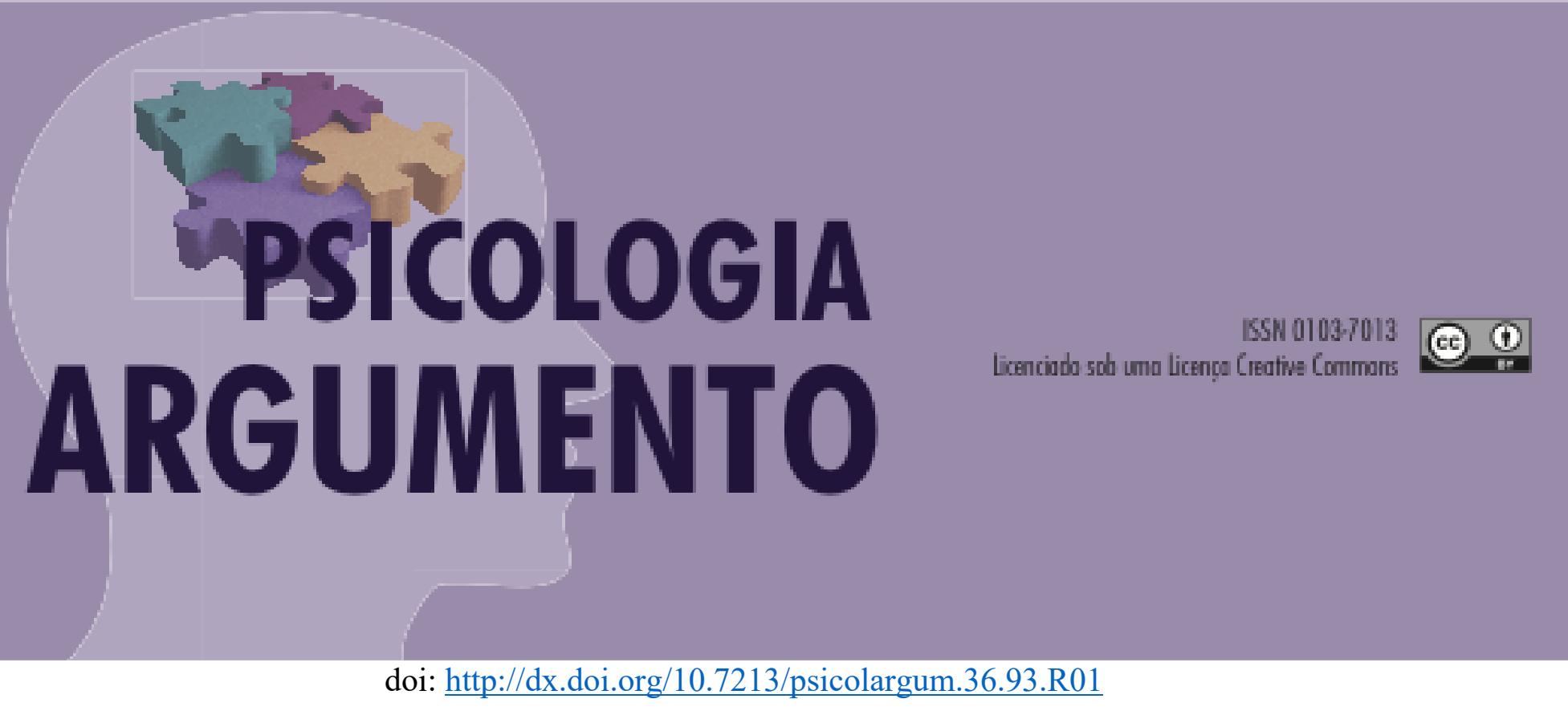

\title{
Adultez Emergente: a estrada sinuosa do final da adolescência aos vinte e poucos anos
}

Emerging Adulthood: the winding road from the late teens through the twenties

Edad adulta emergente: el camino sinuoso desde finales de la adolescencia hasta los años veinte

\section{Sarah Aline Roza}

Mestra e Doutoranda em Educação na Universidade Federal do Paraná (UFPR), Curitiba, PR, Brasil, e-mail: sarah.a.roza@gmail.com

\section{Thiago Henrique Roza}

Médico Residente em Psiquiatria pela (UFRGS), Porto Alegre, RS, Brasil, e-mail:

\section{Josafá Moreira da Cunha}

Doutor em Educação e Professor no Departamento de Teoria e Fundamentos da Educação da Universidade Federal do Paraná (UFPR), Curitiba, PR, Brasil.

Arnett, J. J. Emerging Adulthood: the winding road from the late teens through the twenties. $2^{\circ}$ ed. Oxford: Oxford University Press, 2015.

Conforme mudanças econômicas, políticas e sociais ocorrem em uma taxa acelerada nas primeiras décadas do milênio, também ocorrem alterações na transição para a vida adulta a ponto de um novo processo de desenvolvimento ser necessário para dar conta dessas mudanças. A partir dessas mudanças é preciso reinterpretar os processos de 
transição para a vida adulta. Jeffrey Jesen Arnett (2015), em seu livro: Emerging Adulthood: the winding road from the late teens through the twenties (Adultez Emergente: a estrada sinuosa do final da adolescência aos vinte e poucos anos) situa o leitor, com explicações científicas, quanto à importância de se compreender o fenômeno da adultez emergente não apenas no âmbito da psicologia, mas de forma interdisciplinar. Mas, afinal, qual a importância dessa obra para o cenário nacional?

A população brasileira, à semelhança de outros países, passa por uma mudança em seu regime demográfico, demarcada por uma elevada proporção de jovens adultos na população em comparação à participação de crianças, adultos e idosos. (Unicef, 2012). A adultez emergente se refere a um período de exploração de possibilidades na transição para a vida adulta. Nesse contexto, a obra, de autoria de um pesquisador renomado e respeitado na área da psicologia, a partir de achados empíricos e de pesquisas realizadas ao redor do mundo, não se limita ao contexto acadêmico, trata-se de uma leitura acessível e fluída. Com 13 capítulos, a publicação dessa segunda edição marca um trabalho inovador para o desenvolvimento humano.

O primeiro capítulo, A longer road to adulthood (Um caminho mais longo para a vida adulta), discute as transformações sociais, as quedas nas taxas de mortalidade e fecundidade que vêm ocorrendo em diferentes países e culturas ao redor do mundo, e como essas alterações propiciaram um campo para o surgimento do conceito de adultez emergente. Nesse capítulo, Arnett (2015) define adultez emergente como período de transição entre o final da adolescência e a idade de jovem adulto, a qual emergiu como importante processo de desenvolvimento nos últimos anos, sendo marcado, predominantemente, pela exploração da identidade, instabilidade, foco em si mesmo, sensação de estar em meio a algo e percepção de múltiplas possibilidades.

O segundo capítulo, What is it like to be an emerging adult? (Como é ser um adulto emergente?), apresenta a descrição de quatro pessoas passando pela adultez emergente. Arnett (2015) faz um esforço para explicar o que é a adultez emergente em sua complexidade. O interessante do capítulo é perceber que pessoas de diferentes lugares podem apresentar as características da adultez emergente apontadas no primeiro capítulo, as quais são evidenciadas por desafios na escolha profissional, nos relacionamentos interpessoais e no protelamento ou adiamento do casamento e da parentalidade, aspectos que vêm se tornando comuns para esse processo de instabilidade e múltiplas escolhas. 
No terceiro capítulo, From conflict to companionship: a new relationship with parents (Do conflito ao companheirismo: um novo relacionamento com os pais), há uma contextualização das principais modificações que ocorreram no relacionamento entre pais e filhos na adultez emergente. Arnett (2015) demonstra que, apesar de conflitos na busca de independência financeira e emocional, há uma tendência de os adultos emergentes retornarem à casa dos pais em decorrência de problemas econômicos ou pessoais, além da ausência de saída nesse momento, seja para uma dedicação maior aos estudos, ou por questões econômicas e mesmo por conveniência.

O quarto capítulo, Love and sex: new freedom, new problems (Amor e sexo: novas liberdades, novos problemas), destaca as dificuldades encaradas nas novas formas de se relacionar. Os adultos emergentes são incentivados a uma busca por novas e variadas experiências. Ao mesmo tempo em que há mais possibilidades e escolhas, há mais dificuldades em descobrir qual deve ser o caminho a ser seguido. Arnett (2015) traz dados que mostram como os papéis de gênero, a orientação sexual, as DSTs e a pornografia modificaram a forma das pessoas se relacionarem e acrescentou novos desafios, não ignorados.

O capítulo cinco, intitulado Meandering toward marriage (Trilhando o caminho para o casamento), segue a discussão iniciada no capítulo anterior, adicionando importância à decisão de quando casar. De acordo com dados apresentados, atualmente, os trinta anos passaram a ser a idade mais frequente para os casamentos. Além disso, muitos casais optam pela coabitação ao invés do casamento. Os divórcios se tornaram mais frequentes, pois as pessoas têm mais opções de escolha. A conclusão do capítulo aponta que atitudes de jovens em relação ao casamento passaram por grandes modificações. As pessoas têm diversos sentimentos e experiências diferentes em relação a isso, desde expectativas positivas até o medo de se frustrar e não há uma regra quanto às escolhas.

O sexto capítulo, The road through college: twists and turns (A estrada para a universidade: voltas e mais voltas), demonstra que o ensino superior vem se tornando um caminho cada vez mais comum para os adultos emergentes. Em muitos países, os adultos emergentes entram na faculdade logo após a conclusão de ensino médio e, por vezes, em meio a tantas escolhas, não têm certeza quanto a decisão feita. Além disso, os estudantes estão apresentando uma tendência maior de iniciarem o ensino superior e a permanecer na universidade em busca de mais qualificação para, posteriormente, ocupar uma vaga 
melhor no mercado de trabalho. A tecnologia também transformou o ambiente acadêmico, gerando novas possibilidades de estudos, inclusive para pessoas com menos recursos financeiros. $\mathrm{O}$ ambiente acadêmico figura como espaço para grande parte das explorações típicas da adultez emergente.

O sétimo capítulo, Work: more than a job (Trabalhar: mais do que um emprego), discute o quanto a busca por um emprego tem se modificado, não é apenas algo que pague as contas, mas que traga satisfação e identificação. Arnett (2015) destaca que esses adultos emergentes também precisam pagar contas e se manter, mesmo que estejam morando com os pais, o que os leva a entrarem em empregos temporários que não condizem com a identidade de escolha deles. A conclusão do capítulo é a de que adultos emergentes têm grandes expectativas de encontrarem um emprego compatível com as suas escolhas, mas a realidade, frequentemente, apresenta-se dura e difícil.

O oitavo capítulo, Digital natives: emerging adults' many media uses (Nativos digitais: os diversos usos de mídias por adultos emergentes), enfatiza que a geração de adultos emergentes atuais é a primeira de nativos digitais. Nesse contexto, é constante a presença de celulares e mídias em todos os relacionamentos. As mídias digitais têm modificado os adultos emergentes, sem dúvidas, mas de forma complexa, com benefícios e custos, com resultados diferentes para pessoas diferentes. Contudo, os adultos emergentes têm se beneficiado mais do que prejudicado por essas ferramentas, tanto em na dimensão pessoal, quanto acadêmica e profissional.

O nono capítulo, Sources of meaning: religious beliefs and values (Fontes de sentido: crenças e valores religiosos), demonstra o quanto uma visão de mundo envolve, inevitavelmente, crenças ou religião. Os adultos emergentes, de várias partes do globo, vivem em um momento de maior liberdade. Essa liberdade resulta em uma variedade de crenças e valores, desde os mais conservadores até aos desprendidos. Havendo espaço para aqueles que desenvolvem sua própria forma de crer com base em diversas ideologias e preceitos religiosos. Apesar disso, os adultos emergentes têm uma tendência maior a respeitar outras crenças e valores diferentes dos seus.

O décimo capítulo, How importante is social class? (O quão importante é a classe social?), focaliza sua atenção na associação entre nível econômico e adultez emergente. Alguns teóricos questionam se de fato esse período do desenvolvimento faz sentido para pessoas de níveis socioeconômicos mais baixos. Os achados de Arnett (2015) apontam que a adultez emergente faz parte de diferentes culturas. No Brasil, Dutra-Thome e Koller 
(2014) realizaram uma pesquisa em relação à transição para a vida adulta em brasileiros de diferentes níveis socioeconômicos para ver se a adultez emergente se aplicava aos brasileiros. Os resultados apontaram que mais de $50 \%$ dos jovens se percebem em meio a uma ambivalência quanto a terem atingindo ou não a vida adulta. Entretanto, as autoras destacam que o fenômeno da adultez emergente apresentou uma prevalência maior em contextos de níveis socioeconômicos altos, pois o grupo com níveis socioeconômicos mais baixos demonstrou uma tendência em assumir responsabilidades adultas precocemente, diminuindo a experimentação e as possibilidades presentes na adultez emergente enquanto fenômeno de desenvolvimento humano.

O décimo primeiro capítulo, Wrong turns and dead ends (Direções erradas e becos sem saída), demonstra que a maior parte dos adultos emergentes desejaria estar vivendo o melhor momento de sua vida. Nesse cenário, há uma elevação no índice de problemas externalizados, como crimes, uso de substâncias e problemas com direção. Além do aumento de problemas internalizados, tais como depressão, ansiedade e problemas alimentares. Apesar da elevação nesses quadros apontados, não há regras, há diversos caminhos para as escolhas individuais e cada qual com suas consequências, sejam positivas ou negativas, para o desenvolvimento.

O décimo segundo capítulo, Sometimes goodbye is a second chance: resilience in emerging adulthood (Às vezes, despedidas são segundas chances: resiliência na adultez emergente), aponta que a adultez emergente não é uma fase para os “privilegiados”, como poderia ficar subentendido pelo capítulo 10. Há diversas tendências que surgem para lidar com as múltiplas escolhas e as consequências advindas delas. Esse capítulo deixa evidente a importância da resiliência para os adultos emergentes, pois a transição para a vida adulta não ocorre sem desafios e a instabilidade, bem como as escolhas deste período de desenvolvimento trazem muitas incertezas quanto ao futuro e a capacidade de manejar isso por meio da resiliência se torna uma habilidade social importante a ser desenvolvida. Além disso, a resiliência também atua como importante preditor de saúde mental, satisfação com a vida e orientação quanto ao futuro.

O décimo terceiro capítulo, Beyond emerging adulthood: what does it means to become an adult? (Além da adultez emergente: o que significa se tornar um adulto emergente?), encerra o livro destacando a fluidez e a complexidade da adultez emergente, que vem se consolidando enquanto área de investigação em diversas culturas ao redor do mundo. Os sentimentos que marcam esse período do desenvolvimento trazem questões 
do final da adolescência que se associam a uma transição para a vida adulta, o que sinaliza a exploração e a instabilidade tão marcantes dessa etapa do desenvolvimento.

Ao final do livro, são disponibilizadas todas as notas explicativas sobre as pesquisas realizadas pelo autor do livro e seus colaboradores, bem como por outros pesquisadores que endossam a obra. Certamente, trata-se de uma obra útil para estudantes e pesquisadores, interessante para educadores, e imprescindível para aqueles que detêm o poder de formular e executar políticas públicas, pois a demanda por novas perspectivas sociais, acadêmicas e trabalhistas precisarão ser identificadas e analisadas para um desenvolvimento de qualidade desses adultos emergentes. Nesse cenário, recomenda-se a tradução para a língua portuguesa desse livro extraordinário, para que a obra se torne mais acessível ao público lusófono.

\section{Referências}

Dutra-Thomé, L., \& Koller, S. H. (2014). Emerging Adulthood in Brazilians Socioeconomic Status: Transition to Adulthood. Paidéia, 24(59), 313-322.

United Nations Children's Fund (UNICEF), (February 2012) When the Global Crisis and Youth Bulge Collide: Double the Jobs Trouble for Youth. New York. 